\title{
The Australian National Survey of Mental Health
}

\section{and Well-Being}

\author{
Common psychological symptoms and disablement
}

AILSA KORTEN and SCOTT HENDERSON

\begin{abstract}
Background The mental health of populations can be represented by case prevalence rates and by symptom scales. Scales have the advantage of identifying sub-syndromal levels of distress, which may be common and associated with considerable disability.
\end{abstract}

Aims To examine the distribution of common psychological symptoms and associated disablement in the Australian population.

\section{Method A household sample of 10641 individuals representative of the adult population of Australia was interviewed using the Composite International Diagnostic Interview and completed scales measuring recent symptoms and disablement.}

\section{Results Symptom scales showed similar associations with socio-economic variables as did diagnoses, although only a small amount of variance in symptom levels was explained by these variables. \\ Considerable disablement was associated with symptom levels indicating distress but not reaching levels for formal diagnoses of anxiety or depression.}

\section{Conclusions Symptom scales provide} parsimonious measures of psychological distress and are appropriate for use in large-scale surveys of mental health and disablement.

Declaration of interest No conflict of interest. Funding detailed in

Acknowledgements.
Information about a nation's mental health and ill health is valuable for the administration of health services, for advocacy and for research. It is usually an estimation of the numbers of persons reaching case level according to the diagnostic criteria in ICD-10 (World Health Organization, 1993) or DSM-IV (American Psychiatric Association, 1994). In contrast, continuous measures of symptoms offer some advantages. First, caseness by diagnostic classifications is necessarily arbitrary (Jablensky, 1999). Second, subclinical states are important because of their prevalence, their associated disability, their importance in primary care and their costs to the health care system (Pincus et al, 1999). Third, symptom scales are useful for exploring comorbidity among symptoms, independent of caseness. Last, for population health research, the frequency distribution of symptoms is an indicator of the overall mental health of a community (Rose, 1993). Here we report findings on the distribution of common psychological symptoms and associated disablement in the Australian population.

\section{METHOD}

\section{The Australian National Survey of Mental Health and Well-Being}

In 1997, the Commonwealth Department of Health and Family Services in Australia undertook a National Survey, conducted by the Australian Bureau of Statistics (ABS). The aims, methods and initial findings on diagnostic groups have been reported in detail in previous publications (Andrews et al, 1999; Henderson et al, 2000). The survey data are used here to test two hypotheses:

(a) that socio-demographic associations with symptom status in Australia will be similar to those found in other countries (Robins \& Regier, 1991; Kessler et al, 1994; Jenkins et al, 1997); and specifically that psychological symptom levels in Australia will be higher among women, younger age groups, those of lower socio-economic status, those not in the workforce and those living in metropolitan rather than rural areas;

(b) that an administratively significant proportion of the population is disabled by psychological symptoms that fall short of ICD-10 or DSM-IV diagnostic criteria.

\section{The sample}

Approximately 13600 private dwellings across Australia were selected using stratified multi-stage area sampling to ensure that all persons living in private dwellings aged 18 years and over within each State and Territory in Australia were represented. The size of this population is estimated to be 13.5 million. One person aged 18 years or over was randomly chosen from each dwelling and invited to take part in what the interviewers explicitly told them was "the National Survey of Mental Health and Well-Being".

\section{Measures of symptoms, well-being and disability}

The instrument forming the core of the interview was the Composite International Diagnostic Interview - Automated (CIDIA), Version 2.1 (Robins et al, 1988; Andrews \& Peters, 1998). The authors of the CIDI-A have been primarily intent on establishing diagnoses for most of the syndromes in ICD-10 and DSM-IV. To conserve interview time and costs, skips have been extensively introduced. For example, if neither of two depression screen items was endorsed, the depression module was skipped. As a consequence, it is not possible to obtain frequency counts of symptoms for all respondents.

To go some way to overcoming this handicap, all respondents also completed the 12-item General Health Questionnaire (GHQ-12; Goldberg \& Williams, 1988). Other related measures were the 12 neuroticism items in the Short Form of the Eysenck Personality Questionnaire - Revised (EPQ$\mathrm{R}$; Eysenck et al, 1985) and the Short Form 12 General Health Survey (SF-12; Ware et al, 1996), which provides both a physical and a mental health scale based on responses to 12 questions on limitations owing to health across different domains. Disablement was measured by the two 
items of the Brief Disability Questionnaire (Ormel et al, 1994) that ask, "During the last one month, how many days in total were you unable to carry out your usual activities fully?" and "During the last one month, how many days in total did you stay in bed all or most of the day because of illness or injury?" The larger of these two numbers was taken as the number of 'days out of role', when the respondent was unable to meet social role obligations. In only $1.7 \%$ of the sample did this correspond to the number of days in bed. The interview was further supplemented with additional items, all by self-report, on socio-demographic variables, including education, labour force status and household composition.

\section{Fieldwork}

The ABS selected its most experienced field staff for this national survey and they were given extensive training. The interview was well received by respondents. The survey was conducted between May and August 1997.

\section{Data analysis}

The data were analysed using the STATA 6.0 package (StataCorp, 1999), which makes appropriate adjustments for the different selection probabilities and response rates of the population sample. A series of regression analyses (linear and logistic) were conducted with either the GHQ-12 score or a diagnostic variable as a dependent variable, and the contribution of socio-demographic variables and physical health was evaluated. A similar series of analyses investigated the predictors of disablement as measured by days out of role. The possible effects of the highly skewed distributions of the GHQ-12 score and days out of role were investigated by careful examination of the regression diagnostics and analyses using alternative negative binomial models. These indicated that the models proposed were satisfactory.

\section{RESULTS}

Interviews were completed on 10641 persons, representing a response rate of $78 \%$. No information is available on the sociodemographic characteristics of the nonresponders. The means and standard errors for measures of psychological and physical health and of disablement are shown in
Table 1. The GHQ-12, SF-12 mental health scale, the EPQ-R neuroticism score and the depression screen items all indicated poorer mental health in women than in men.

\section{Age trends}

There was a trend for symptoms to be fewer among the older age groups. The decline was greater among women than men, so that gender differences in the oldest age groups were reduced. This is illustrated in Fig. 1, which shows the standardised GHQ-12 score by age and gender. Between the ages of 18 and 25 years, the GHQ-12 score increased for men but decreased for women. The prevalence of a diagnosis of any ICD-10 anxiety or depressive disorder followed a similar pattern. It was higher in women than men, with declines for both men and women after the age of 55 years.

Given the different pattern of responses by age and gender, subsequent regression analyses treated age group as a categorical variable and men and women were analysed separately.

\section{Symptoms and socio-demographic variables}

Independent variables studied included age, educational qualifications, occupation, urban/ rural residence, marital status, labour force status, main source of income, housing tenure and household type. Men and women differed in their distributions across each of the independent variables, except for urban/rural residence $\left(P<0.01\right.$ on $\chi^{2}$ tests). The GHQ-12 scores were compared across categories using analyses of variance and adjusting for age group. There were no significant differences by educational qualification or occupational class. Mean GHQ12 scores were significantly different $(P<0.01)$ for both men and women across categories of marital status, urban/rural residence, labour force status, housing tenure, main source of income and household type (see Table 2).

When all variables were included in a regression, only a small proportion of the overall variance was explained. For men, only age, rural residence, labour force

Table I Measures of psychological and physical health and disablement

\begin{tabular}{|c|c|c|c|}
\hline \multirow[t]{2}{*}{ Measure } & Men & Women & Both \\
\hline & Mean (s.e.) or \% (s.e.) & Mean (s.e.) or \% (s.e.) & Mean (s.e.) or \% (s.e.) \\
\hline \multicolumn{4}{|l|}{ Mental health scales } \\
\hline GHQ-I2 & $0.83(0.05)$ & $\mathrm{I} .02(0.03)$ & $0.92(0.03)$ \\
\hline SF-12 mental scale ${ }^{\prime}$ & $52.6(0.2)$ & $5 \mathrm{I} .4(0.1)$ & $52.0(0.1)$ \\
\hline $\begin{array}{l}\text { Number of endorsed screen } \\
\text { items for depression (0-2) }\end{array}$ & $0.2 \mathrm{I}(0.0 \mathrm{I})$ & $0.27(0.01)$ & $0.24(0.0 \mathrm{I})$ \\
\hline EPQ-R neuroticism & $2.31(0.05)$ & $2.88(0.06)$ & $2.59(0.03)$ \\
\hline \multicolumn{4}{|l|}{ Diagnoses } \\
\hline $\begin{array}{l}\text { Any ICD-I0 diagnosis of } \\
\text { anxiety or depressive } \\
\text { disorder }(\%)^{2}\end{array}$ & $9.9(0.6)$ & $16.9(1.1)$ & $13.5(0.6)$ \\
\hline $\begin{array}{l}\text { ICD-I0 diagnosis of alcohol } \\
\text { or drug harmful use or } \\
\text { dependence }(\%)\end{array}$ & II.0(I.0) & $4.5(0.3)$ & $7.7(0.6)$ \\
\hline \multicolumn{4}{|l|}{ Disablement (days out of role) } \\
\hline $\begin{array}{l}\text { Mean number of days } \\
\text { affected by disablement in } \\
\text { past month }\end{array}$ & $1.72(0.13)$ & $2.05(0.08)$ & $1.89(0.09)$ \\
\hline \multicolumn{4}{|l|}{ Physical health measures } \\
\hline $\begin{array}{l}\text { Chronic medical condition } \\
\text { (\%) }\end{array}$ & $35.9(0.8)$ & $4 I . I(I .3)$ & $38.6(0.7)$ \\
\hline SF-12 physical scale' & $49.4(0.3)$ & $48.7(0.2)$ & $49.1(0.2)$ \\
\hline
\end{tabular}



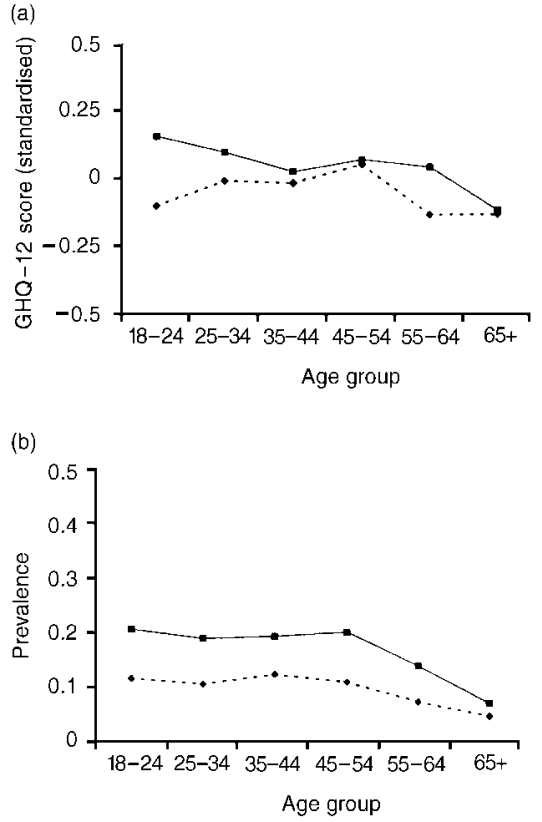

Fig. I The (a) 12-item General Health

Questionnaire (GHQ-12) score (standardised) and (b) prevalence of ICD-10 anxiety or depressive diagnoses, by age and gender: (-- --) males; (- - ) females.

status and household type remained significantly related to GHQ-12 score, and the total explained variance $\left(R^{2}\right)$ was $4.9 \%$. For women, only $3.7 \%$ of variance was explained by all variables, with only age, marital status, labour force status, housing tenure and household type remaining significant $(P<0.01)$.

Neuroticism measures a trait that confers vulnerability to anxiety and depression, although it is also affected by current symptom states (Clark et al, 1994). It could therefore be argued that some of the differences in symptoms could be a result of the differences in the underlying trait of neuroticism. When neuroticism was included in the regression, the variance explained increased to $19.6 \%$ for men and $15.6 \%$ for women, whereas the associations with the socio-demographic variables remained almost unchanged. Similarly, adding physical health (SF-12 physical health scale and number of chronic medical conditions) explained additional variance in GHQ-12 scores $(1.3 \%$ for men and $1.7 \%$ for women), but differences in the other independent variables again remained almost unchanged.

\section{Predictors of ICD-10 anxiety and depressive disorders}

A series of logistic regression analyses were conducted to investigate the contribution of

Table 2 Estimated population distribution and the distribution of 12-item General Health Questionnaire (GHQ-12) scores by demographic and socio-economic variables

\begin{tabular}{|c|c|c|c|c|c|c|}
\hline \multirow[t]{2}{*}{ Variable' } & \multicolumn{3}{|c|}{ Men $(n=4705)$} & \multicolumn{3}{|c|}{ Women $(n=5936)$} \\
\hline & $\%$ & \multicolumn{2}{|c|}{$\begin{array}{c}\text { Estimated mean } \\
\text { GHQ-12 score (s.e.) }\end{array}$} & $\%$ & \multicolumn{2}{|c|}{$\begin{array}{c}\text { Estimated mean } \\
\text { GHQ-12 score (s.e.) }\end{array}$} \\
\hline \multicolumn{7}{|l|}{ Urban/rural residence } \\
\hline $\begin{array}{l}\text { Capital city and other metropolitan } \\
\text { areas (pop. }>100000)\end{array}$ & 71.9 & 0.86 & $(0.05)$ & 73.3 & 1.07 & $(0.04)$ \\
\hline Large/small rural centres & 12.1 & 0.94 & $(0.16)$ & 11.9 & 0.97 & $(0.11)$ \\
\hline Other rural areas (pop. $<10000$ ) & 15.9 & 0.64 & $(0.05)^{2}$ & 14.8 & 0.84 & $(0.07)^{2}$ \\
\hline \multicolumn{7}{|l|}{ Marital status } \\
\hline Married & 60.9 & 0.79 & $(0.10)$ & 57.5 & 0.93 & $(0.07)$ \\
\hline De facto, cohabiting & 6.0 & 0.72 & $(0.15)$ & 5.9 & 1.05 & $(0.14)$ \\
\hline Separated & 2.3 & 1.13 & $(0.24)^{2}$ & 3.4 & 1.71 & $(0.25)^{2}$ \\
\hline Divorced & 4.0 & 1.15 & $(0.24)^{2}$ & 6.4 & 1.11 & $(0.15)$ \\
\hline Widowed & 2.2 & 0.74 & $(0.12)$ & 9.0 & 0.81 & $(0.09)$ \\
\hline Never married & 24.5 & 0.88 & $(0.06)$ & 17.9 & 1.24 & $(0.14)$ \\
\hline \multicolumn{7}{|l|}{ Labour force status } \\
\hline Employed full-time & 62.6 & 0.70 & $(0.04)$ & 28.7 & 0.93 & $(0.06)$ \\
\hline Employed part-time & 9.5 & 0.92 & $(0.10)^{2}$ & 26.1 & 0.97 & $(0.05)$ \\
\hline Short-term not employed ( $<6$ months) & 3.2 & 1.72 & $(0.28)^{2}$ & 2.6 & 1.55 & $(0.24)$ \\
\hline Long-term not employed ( $>6$ months) & 1.8 & 1.72 & $(0.53)^{2}$ & 0.7 & 1.94 & $(1.28)$ \\
\hline Not in the labour force & 22.9 & 0.97 & $(0.11)^{2}$ & 41.8 & 1.07 & $(0.05)^{2}$ \\
\hline \multicolumn{7}{|l|}{ Main source of income } \\
\hline Wage or salary & 53.8 & 0.72 & $(0.03)$ & 42.8 & 0.93 & $(0.04)$ \\
\hline $\begin{array}{l}\text { Any government pension, allowance } \\
\text { or benefit }\end{array}$ & 21.5 & 1.08 & $(0.11)^{2}$ & 34.7 & 1.16 & $(0.05)^{2}$ \\
\hline Other income & 24.7 & 0.87 & $(0.11)^{2}$ & 22.5 & 0.99 & $(0.08)^{2}$ \\
\hline \multicolumn{7}{|l|}{ Housing tenure } \\
\hline Owner & 30.2 & 0.73 & $(0.07)$ & 33.5 & 0.76 & $(0.04)$ \\
\hline Purchaser & 32.4 & 0.80 & $(0.10)$ & 32.1 & 1.04 & $(0.10)^{2}$ \\
\hline Renter & 25.6 & 0.98 & $(0.06)^{2}$ & 24.4 & 1.29 & $(0.07)^{2}$ \\
\hline Other & 11.7 & 0.85 & $(0.11)$ & 10.0 & 1.16 & $(0.24)$ \\
\hline \multicolumn{7}{|l|}{ Household type } \\
\hline Person living alone or with children & 14.5 & 1.06 & $(0.08)$ & 21.7 & 1.19 & $(0.06)$ \\
\hline Couple with or without children & 71.6 & 0.77 & $(0.06)^{2}$ & 65.2 & 0.93 & $(0.05)^{2}$ \\
\hline Other households & 14.0 & 0.93 & $(0.12)$ & 13.1 & 1.22 & $(0.12)$ \\
\hline
\end{tabular}

I. There is a significant difference between all categories when controlling for age group $(P<0.01)$.

2. Significantly different from the first category, which is taken as the reference category.

GHQ-12 score to the prediction of an ICD-10 diagnosis of anxiety or depressive disorder. Adjustments were made for sociodemographic predictors, with age, marital status, labour force status, education and physical health being significant. Place of residence, occupation, source of income or type of household were not significant. With each unit increase in the GHQ-12 score, the adjusted odds of a diagnosis increased by about $50 \%$ for men (adjusted $\mathrm{OR}=1.49$, $95 \%$ CI $1.42-1.57)$ and $40 \%$ for women (adjusted OR=1.39, 95\% CI 1.34-1.44).
Although the probability of a diagnosis increases rapidly with GHQ-12 score, a substantial number of persons who have high levels of symptoms have no diagnosis. Table 3 shows the percentage of the total population estimated to have a CIDI-A diagnosis of anxiety or depression, by GHQ-12 score, after adjusting for sociodemographic variables. A GHQ-12 score of 2 or more may be taken to indicate psychological distress in populations where the mean GHQ-12 score lies between 1 and 2 . Although $19.4 \%$ of the Australian adult 
Table 3 Estimated population' distribution (\% (s.e.)) by ICD-10 diagnosis (anxiety or depressive disorder) using the 12-item General Health Questionnaire (GHQ-12) score

\begin{tabular}{lccc}
\hline $\begin{array}{l}\text { GHQ-I2 } \\
\text { score }\end{array}$ & $\begin{array}{c}\text { NoICD-I0 } \\
\text { diagnosis }\end{array}$ & $\begin{array}{c}\text { ICD-I0 } \\
\text { diagnosis }\end{array}$ & Total \\
\hline 0 & $6 I .6(0.6)$ & $5.0(0.5)$ & $66.6(0.9)$ \\
I & $11.9(0.6)$ & $2.2(0.2)$ & $14.1(0.5)$ \\
2 or more & $13.1(0.5)$ & $6.3(0.3)$ & $19.4(0.5)$ \\
Total & $86.6(0.6)$ & $13.5(0.6)$ & 100.0 \\
\hline
\end{tabular}

I. Total adult population is estimated to be 13.5 million.

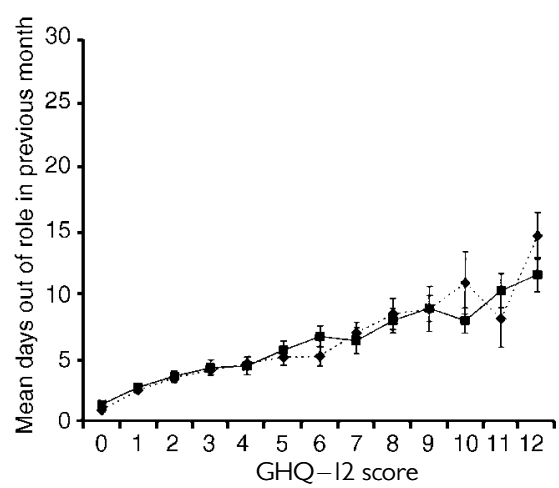

Fig. 2 Estimated mean days out of role in month prior to interview, and $95 \% \mathrm{Cl}$, adjusting for age, physical health and other socio-demographic variables, by 12-item General Health Questionnaire (GHQ-12) score: (-- --) no diagnosis; ( $-\square)$ diagnosis.

population fell into this category, only onethird of these $(6.3 \%)$ actually received a diagnosis of anxiety or depression. That is, $13.1 \%$ of the population are estimated to have a GHQ-12 score indicating distress but do not have a diagnosis of anxiety or depression.

\section{Disablement}

In the total sample, days out of role were higher among women (mean $=2.05$, s.e. $=0.08)$ than among men (mean $=1.72$, s.e. $=0.08)$ and increased with age. Analyses indicated that there were no significant interactions of predictors with gender, so men and women were analysed together. A series of regression analyses investigated the contribution of symptoms to disablement after controlling for age, physical health and other socio-demographic variables. It was found that after controlling for age, physical health and labour force status, the number of depression screen items endorsed explained an additional $1.2 \%$ of the variance $(B=0.38$, s.e. $=0.11)$ and the GHQ-12 score $3.4 \%$ of variance $(B=0.56$, s.e. $=0.05)$. Total explained variance was $31.4 \%$. A diagnosis of substance use was not associated with disablement. The only social indicator that was significant was labour force status: not being in the labour force was associated with increased disablement $(B=0.73$, s.e. $=0.16$ ). None of the other social indicators was significant, and nor was neuroticism once the GHQ-12 score was included.

It was notable that once the GHQ-12 score and depression screen items were included as independent variables, a diagnosis of depression or anxiety did not add significantly to the prediction of disablement. The estimated mean number of days out of role in the previous month for different levels of GHQ-12 symptoms is illustrated in Fig. 2. The total estimated number of such disability days in the population is shown in Table 4. The burden of disablement carried by the $13.1 \%$ of the population who have high GHQ-12 symptoms but who do not have a diagnosis of anxiety or depressive disorder (7.4 million days) is similar to the total burden carried by the $13.5 \%$ of the population who received a diagnosis (7.1 million days). Together the two groups with impaired mental health, accounting for $26.6 \%$ of the population, are associated with $57 \%$ of the disablement for the total population. This estimate does not necessarily include disablement associated with persons with other psychiatric diagnoses such as schizophrenia.

\section{DISCUSSION}

This report provides information on impaired mental health for a whole country. By focusing on symptoms rather than diagnostic categories, it complements previous reports from the National Survey dealing with the prevalence of ICD-10 disorders in the same population.

\section{Response}

The response rate of $78 \%$ is close to that achieved in other national surveys (Robins \& Regier, 1991; Kessler et al, 1994; Jenkins et al, 1997). Data have not yet been made available on non-responders. The sample may be biased downwards in morbidity because non-responders are more likely to have symptoms (Kessler et al, 1995).

\section{Symptoms in relation to socio-demographic factors}

Mental ill health as indicated by the GHQ12 is worse in women than men, in younger age groups and in larger rural areas and

Table 4 Estimated total number of days out of role (in millions of days) in month prior to interview for the total adult population, by diagnosis and I2-item General Health Questionnaire (GHQ-12) score

\begin{tabular}{|c|c|c|c|c|c|c|c|c|c|}
\hline \multirow{2}{*}{$\begin{array}{l}\text { GHQ-12 } \\
\text { score }\end{array}$} & \multicolumn{3}{|c|}{ No ICD-I0 anxiety or depressive diagnosis } & \multicolumn{3}{|c|}{ ICD-I0 anxiety or depressive diagnosis } & \multicolumn{3}{|c|}{ Total } \\
\hline & $\begin{array}{c}\% \text { of total } \\
\text { population' }\end{array}$ & $\begin{array}{l}\text { Total days } \\
\text { out of role } \\
(95 \% \mathrm{Cl})\end{array}$ & $\begin{array}{c}\text { Mean days } \\
\text { out of role } \\
(95 \% \mathrm{Cl})\end{array}$ & $\begin{array}{c}\% \text { of total } \\
\text { population' }\end{array}$ & $\begin{array}{c}\text { Total days } \\
\text { out of role } \\
(95 \% \mathrm{Cl})\end{array}$ & $\begin{array}{c}\text { Mean days } \\
\text { out of role } \\
(95 \% \mathrm{Cl})\end{array}$ & $\begin{array}{c}\% \text { of total } \\
\text { population' }\end{array}$ & $\begin{array}{l}\text { Total days } \\
\text { out of role } \\
(95 \% \mathrm{Cl})\end{array}$ & $\begin{array}{c}\text { Mean days } \\
\text { out of role }{ }^{2} \\
(95 \% \mathrm{Cl})\end{array}$ \\
\hline 0 or I & 73.5 & $10.8(9.7-12.0)$ & I.I (0.9-I.2) & 7.2 & $1.9(1.6-2.3)$ & $2.0(1.5-2.5)$ & 80.7 & $12.8(|1.5-| 4.0)$ & I.2(I.I-I.3) \\
\hline 2 or more & 13.1 & $7.4(6.3-8.5)$ & $4.2(3.7-4.7)$ & 6.3 & $5.2(4.3-6.1)$ & $6.2(5.3-7.1)$ & 19.4 & $12.6(\mid I .1-14.2)$ & $4.8(4.4-5.3)$ \\
\hline Total & 86.6 & $18.3(16.6-20.0)$ & $\mathrm{I} .6(\mathrm{I} .4-\mathrm{I} .7)$ & 13.5 & $7.1(6.0-8.2)$ & $3.9(3.3-4.6)$ & 100.1 & $25.4(23.1-27.7)$ & $1.9(1.7-2.1)$ \\
\hline
\end{tabular}

I. Total adult population is estimated to be 13.5 million.

2. In millions of days for a period of I month. 
urban centres. These are consistent findings in many surveys measuring both symptoms and diagnoses of anxiety and depression (Jenkins et al, 1997). The decrease in symptoms in older age groups persisted once other age-dependent risk factors were controlled. This is again consistent with findings in many studies for both symptoms and diagnoses (Jorm, 2000).

Women who were separated had poorer mental health according to their GHQ-12 scores and had significantly higher mean scores than the divorced, whose scores were no different from those of married women. This may be because women who are separated are younger than the divorced, so the marital breakdown may be more recent and they may experience greater financial insecurity and a greater burden of child care than the already divorced. Among men, there was no difference between the separated and divorced, both of whom had higher GHQ12 scores than men who were married or in a de facto relationship. Marital disruption has been found elsewhere to differ in its effect on men and women (Bruce $\&$ Kim, 1992).

The household a person belongs to is also an important indicator of relative mental health. Those living in a household consisting of a couple, with or without children, had better mental health than those living alone or in a household consisting of one person with his or her children. When adjustments were made for other covariates, this difference remained significant. Differences by marital status remained significant only for women once household composition was accounted for, implying that protection conferred on those in stable relationships may come more from the resultant living arrangements than from the marital relationship itself (Kramer et al, 1987). Those living alone or as single parents have been identified as vulnerable in several studies (Rodgers, 1991; Jenkins et al, 1997).

\section{Symptoms and socio-economic factors}

In this Australian sample, symptoms were not found to be related to specific level or type of occupation or level of education. Mental health as indicated by the GHQ12 is better in the full-time employed of both genders. This is a consistent finding across many studies (Rodgers, 1991; Jenkins et al, 1997; Weich \& Lewis, 1998a,b). Men in full-time employment had lower GHQ-12 scores than men in part-time employment; but women in part-time employment had the same low level of symptoms as those in full-time employment, possibly reflecting different family roles. For men, mental distress associated with less than full-time work or with unemployment is particularly strong in the youngest age groups (18-24 and 25-34 years) and may be a reflection of associated financial difficulties. There was no indication that the length of unemployment affected GHQ-12 scores.

Further evidence of the importance of financial difficulties is that people on a pension, especially in the younger age groups, and those in rented accommodation have higher GHQ-12 scores. In Australia, the majority (66\%) of the population either own or are in the process of purchasing their home. To be renting is likely to be associated with being young, with economic disadvantage or with having recently moved. The finding is congruent with those of Rodgers (1991) and Weich and Lewis $(1998 a, b)$, who found that measures of financial difficulties or standard of living rather than measures of education or occupational class were associated with poorer mental health.

The most surprising finding of all is that only a tiny amount of the variance in GHQ-12 score was explained by all of the socio-demographic variables taken together: $4.7 \%$ in men and $3.7 \%$ in women. Although there are statistically significant differences in GHQ-12 scores by sociodemographic characteristics, these differences account for very little of the variance, implying that changes in the sociodemographic profile of the population, undertaken as a public health intervention, would make small differences in the overall distribution of mental ill health. This does not mean that specific subgroups, such as the unemployed, would not experience considerable improvement in mental health were their conditions to change.

\section{Symptoms and being a case}

The GHQ-12 questionnaire, which is usually completed in under 3 minutes, is a highly parsimonious measure of the probability of having an ICD-10 anxiety or depressive disorder. The average time taken to complete the anxiety and depression sections of the CIDI-A was 14 minutes, but up to 1 hour for those passing the screen.
The CIDI-A provides no information on sub-syndromal levels of symptoms, except the screening questions. But, more important for population studies, the GHQ-12 provides an adequate measure of symptoms for those who may not reach the diagnostic threshold. Although the present study is only cross-sectional in design, it has been shown repeatedly (Horwath et al, 1992) that persons with sub-threshold symptoms are at increased risk of developing a future diagnosable depressive disorder. The GHQ12 therefore has the capacity readily to identify persons at risk of further mental health impairment.

\section{Symptoms and disablement}

The GHQ-12 score is closely associated with disablement in daily life, expressed as the number of days in the previous month with social role impairment (Fig. 2 ). The regression analyses show that after symptoms were known, whether or not the person had a diagnosis of anxiety or depression did not influence the amount of disablement. The significance of this is that some future population studies of mental health that focus specifically on disablement need not include detailed psychiatric assessments. As has been found elsewhere (Broadhead et al, 1990), where the concern is to identify the population levels of disablement associated with impaired mental health, a symptom measure is more appropriate than diagnoses alone. The GHQ-12 serves well for this purpose.

Because there are many more individuals with symptoms than with ICD-10 diagnoses, the total burden of disablement in the community in symptomatic persons is greater than in the formal ICD-10 cases of anxiety and depression: in 1 month, in a population of 13.5 million people, there were estimated to be 7.4 million and 7.1 million days out of role, respectively. Adding these two together, in one month, there were 14.5 million days with disablement associated with mental ill health. This stands in contrast to the 10.9 million days of disablement in mentally healthy persons who had both low GHQ-12 scores and no ICD-10 diagnosis of anxiety or depression. In interpreting these data, it would be unjustified to attribute all of the 14.5 million days of disablement to impaired mental health. This is because of comorbidity with physical disorders, which is known to be considerable in this sample (Andrews et al, 1999). But the findings suggest that: 
there is a strong association between impaired mental health and impaired social role performance; and the group in the population who have sub-syndromal symptoms carry at least half of this burden of disablement. The administrative significance of these observations cannot be overestimated, because they provide powerful evidence to justify changes in the deployment of health service resources, especially to primary care, to reduce the disablement associated with impaired mental health.

\section{ACKNOWLEDGEMENTS}

This study was supported by grant 973302 from the National Health and Medical Research Council to the Centre and a grant from the Mental Health Branch of the Commonwealth Department of Health and Aged Care, who also funded the National Survey. The authors were employees of Australian National University and no other funds were obtained. Data used in this study are from the Australian Bureau of Statistics. Results or views expressed are those of the authors and not necessarily those of the Bureau.

\section{REFERENCES}

American Psychiatric Association (1994) Diagnostic and Statistical Manual of Mental Disorders (4th edn) (DSM-IV).Washington, DC: APA.

Andrews, G. \& Peters, L. (1998) The psychometric properties of the Composite International Diagnostic Interview. Social Psychiatry and Psychiatric Epidemiology, 33, $80-88$.

_ , Hall, W., Teesson, M., et al (1999) The Mental Health of Australians. Canberra: Commonwealth Department of Health and Aged Care.

Broadhead, W. E., Blazer, D. G., George, L. K., et al (1990) Depression, disability days, and days lost from work in a prospective epidemiologic survey. Journal of the American Medical Association, 264, 2524-2528.

Bruce, M. L. \& Kim, K. M. (1992) Differences in the effects of divorce on major depression in men and women. American Journal of Psychiatry, 149, 914-917.

\section{Clark, L. A., Watson, D. \& Mineka, S. (1994)}

Temperament, personality, and the mood and anxiety disorders. Journal of Abnormal Psychology, 103, 103-116.

Eysenck, S. B. G., Eysenck, H. J. \& Barrett, P. (1985) A revised version of the psychoticism scale. Personality and Individual Differences, 6, 21-29.

Goldberg, D. P. \& Williams, P. (1988) A User's Guide to the GHQ. London: NFER Nelson.

Henderson, A. S., Andrews, G. \& Hall, W. (2000) Australia's mental health: an overview of the general population survey. Australian and New Zealand Journal of Psychiatry, 34, 197-205.

Horwath, E., Johnson, J., Klerman, G. L., et al (1992) Depressive symptoms as relative and attributable risk factors for first-onset major depression. Archives of General Psychiatry, 49, 817-823.

Jablensky, A. (1999) Classifications in psychiatry: issues beyond ICD-10 and DSM-IV. Australian and New Zealand Journal of Psychiatry, 33, 137-144.

\section{CLINICAL IMPLICATIONS}

- Socio-demographic variables account for little of the total variation in mental ill health as measured by symptom scales, despite strong statistical associations.

- Considerable disablement is found at levels of morbidity below those defined by the diagnostic criteria in international use. Reliance only on cases fulfilling these can be misleading for clinical, administrative and research purposes.

- The GHQ-12 is a parsimonious but effective measure of mental ill health in community-based studies.

\section{LIMITATIONS}

The study was cross-sectional.

- Measures of symptoms and disablement are by self-report only. The measurement of disablement is crude.

- Twenty-two per cent of the target sample refused or were not available and some ethnic groups were necessarily underrepresented.

AILSA KORTEN, BSc, SCOTT HENDERSON, FRCPsych, Centre for Mental Health Research, The Australian National University, Canberra, Australia

Correspondence: Ailsa Korten, Centre for Mental Health Research, The Australian National University, Canberra, A.C.T. 0200, Australia; e-mail: ailsa.korten@anu.edu.au

(First received 14 October 1999, final revision 4 May 2000, accepted 9 May 2000)

Jenkins, R., Lewis, G., Bebbington, P., et al (1997) The National Psychiatric Morbidity Surveys of Great Britain - initial findings from the Household Survey. Psychological Medicine, 27, 775-789.

Jorm, A. F. (2000) Does old age reduce anxiety and depression? A review of epidemiological studies across the life span. Psychological Medicine, 30, II-22.

Kessler, R. C., McGonagle, K. A., Zhao, S., et al (1994) Lifetime and I2-month prevalence of DSM-III-R psychiatric disorders in the United States: results from the National Comorbidity Survey. Archives of General Psychiatry, 51, 8-19.

_, Little, R. J. A. \& Groves, R. M. (1995) Advances in strategies for minimizing and adjusting for survey nonresponse. Epidemiologic Reviews, 17, 192-204.

Kramer, M., Brown, H., Skinner, A., et al (1987) Changing living arrangements in the population and their potential effect on the prevalence of mental disorder: findings of the Eastern Baltimore Mental Health Survey. In Psychiatric Epidemiology: Progress and Prospects (ed. B. Cooper), pp. 3-26. London: Croom-Helm.

Ormel, J., VonKorff, M., Üstün, B., et al (1994) Common mental disorders and disability across cultures. Results from the WHO Collaborative Study on Psychological Problems in General Health Care. Journal of the American Medical Association, 272, 1741-1748.

Pincus, H. A., Davis, W. W. \& McQueen, L. E. (1999) 'Subthreshold' mental disorders. A review and synthesis of studies on minor depression and other 'brand names'. British Journal of Psychiatry, 174, 288-296.
Robins, L. N. \& Regier, D. A. (199I) Psychiatric Disorders in America. New York: The Free Press.

\section{_ , Wing, J., Wittchen, H-U., et al (1988) The} Composite International Diagnostic Interview. Archives of General Psychiatry, 45, 1069-1077.

Rodgers, B. (1991) Socio-economic status, employment and neurosis. Social Psychiatry and Psychiatric Epidemiology, 26, 104-114.

Rose, G. (1993) Mental disorder and the strategies of prevention [Editorial]. Psychological Medicine, 23, 553-555.

StataCorp (1999) Stata Statistical Software: Release 6.0. College Station, TX: Stata Corporation.

Ware, J., Jr., Kosinski, M. \& Keller, S. D. (1996) A I2Item Short-Form Health Survey: construction of scales and preliminary tests of reliability and validity. Medical Care, 34, 220-233.

Weich, S. \& Lewis, G. (1998a) Poverty, unemployment, and common mental disorders: population based cohort study. British Medical Journal, 317, I15-119.

_ \& _ (1998b) Material standard of living, social class, and the prevalence of the common mental disorders in Great Britain. Journal of Epidemiology and Community Health, 52, 8-14

World Health Organization (1993) The ICD-10 Classification of Mental and Behavioural Disorders. Diagnostic Criteria for Research. Geneva: WHO. 